\title{
Effects of Resveratrol on Inflammation and Apoptosis After Experimental Spinal Cord Injury
}

\author{
Salim SENTURK ${ }^{1}$, Mesut Emre YAMAN², Hasan Emre AYDIN³,4, Guven GUNEY ${ }^{5}$, Ismail BOZKURT ${ }^{6}$, \\ Kemal PAKSOY ${ }^{7}$, Ahmet Atilla ABDIOGLU ${ }^{8}$
}

${ }^{1}$ Koc University Hospital, Department of Neurosurgery, Istanbul, Turkey

${ }^{2}$ Memorial Hospital, Neurosurgery Clinic, Ankara, Turkey

${ }^{3}$ Dumlupinar University, Department of Neurosurgery, Kutahya, Turkey

${ }^{4}$ Osmangazi University, Department of Pharmacology, Eskisehir, Turkey

${ }^{5}$ Hitit University, Research and Training Hospital, Department of Pathology, Corum, Turkey

${ }^{6}$ Cankiri State Hospital, Neurosurgery Clinic, Cankiri, Turkey

${ }^{7}$ Kackar State Hospital, Neurosurgery Clinic, Rize, Turkey

${ }^{8}$ Recep Tayyip Erdogan University, Department of Orthopaedic Surgery, Rize, Turkey

\section{ABSTRACT}

AIM: To determine the effects of resveratrol on inflammation and apoptosis after experimental spinal cord injury (SCI).

MATERIAL and METHODS: Eighteen Sprague-Dawley rats were randomly divided into three groups. All groups underwent thoracic laminectomy. The first group received no other intervention. The second and third groups suffered $\mathrm{SCl}$ via the aneurysm clip compression method, and additionally the third group received resveratrol. After euthanizing the rats, immunohistochemical analysis and biochemical parameters of tumor necrosis factor alpha (TNF-a) and interleukin (IL)-1 $\beta$ were measured.

RESULTS: The resveratrol group had statistically significant lower levels of TNF-a, IL -1 $\beta$, and terminal deoxynucleotidyl transferasemediated dUTP nick-end labeling (TUNEL) positive cells and higher number of glial and motor neuron cells.

CONCLUSION: Resveratrol proves to have remarkable neuroprotective effects on $\mathrm{SCl}$ in an experimental model in addition to its proven cardioprotective effects.

KEYWORDS: Neuroprotection, Neuroregeneration, Rat, Resveratrol, Spinal cord injury, TUNEL

\section{INTRODUCTION}

0 pinal cord injury (SCl) is a catastrophic, multistep cascade that causes various symptoms and morbidities. It was first defined in the ancient Egyptian Edwin Smith Papyrus from 2500 BC (16) and was thought to be untreatable with mortality rates reaching up to $80 \%$ until the $20^{\text {th }}$ century (9). Developments in imaging, surgery, medicine, and rehabilitation contributed to a considerable improvement in $\mathrm{SCl}$ management. Neuroprotection and neuroregeneration are subjects of intense interest given the inevitability of the primary injury caused by trauma (21).
$\mathrm{SCl}$ is categorized into two phases: the primary phase in which the direct trauma of contusion, shear injury, or compression causes a disturbance in the neural tissue and the secondary phase which starts within minutes after the initial trauma. In the secondary phase, various mechanisms such as inflammation, edema, ischemia, and hypoxemia cause gradual deterioration (12). Several studies on SCl focus on preventing the damage caused by the secondary phase.

3,5,4'-trihydroxy-trans-stilbene (Resveratrol), a stilbenoid, is a natural phenol and a phytoalexin found in grapes, raspberries, blueberries, and peanuts, which functions in response to 
trauma or injury (10). It was first discovered in Japan in 1939 (25), and has become popular and even labeled as the "miraculous molecule" at the beginning of the $21^{\text {st }}$ century. Leading pharmaceutical brands have focused on the molecule; numerous studies have investigated its effects on cancer $(4,6)$, Alzheimer's disease (26), heart diseases (24), diabetes (15), and depression (22). Subsequently, resveratrol has become popular along with red wine as it contains the highest level of trans-resveratrol (23).

Resveratrol diminishes the oxidation of low-density lipoproteins by chelating copper and phagocytosis of oxygen-free radicals. Furthermore, it disrupts platelet aggregation formation, thereby decreasing the rate of thrombus formation. It alters arachidonic acid metabolism and inhibits protein kinase activities, thereby proving its anti-inflammatory, anti-bacterial, and anti-apoptotic effects (27).

Numerous studies on resveratrol have focused on its effects after $\operatorname{SCI}(7,13,14,17,20,27,29)$. These studies have targeted resveratrol's effects on oxidative stress, anti-inflammatory process, and apoptosis. During the subacute phase of $\mathrm{SCl}$, rapid and extreme oxidative stress causes necrosis of neurons, leading to diminished blood flow followed by an inflammatory response. In addition, apoptosis worsens the primary injury by obliterating neurons, oligodendrocytes, microglia, and astrocytes (29). Thus, the present study focuses on resveratrol's effects on tumor necrosis factor alpha (TNF-a), interleukin-1 beta (IL-1 $\beta$ ), and motor neuron, glial cell, and apoptotic cell counts after experimental spinal trauma on rats.

\section{MATERIAL and METHODS}

The experimental procedures on the subjects were performed at the TICAM Experimental Animals Laboratory of Osmangazi University School of Medicine. Tissue preparation for histological analysis was carried out at the Department of Pathology, Hitit University, and immunohistochemical analysis was performed at the Department of Pharmacology, Osmangazi University. The experiment was approved by the Experimental Animals Ethical Committee of Osmangazi University (384/2014).

A total of 18 female Sprague-Dawley rats weighing 200-250 g were used. They were divided randomly and equally into three groups: control, trauma, and resveratrol. The animal subjects received $60 \mathrm{mg} / \mathrm{kg}$ of ketamine hydrochloride intraperitoneally (IP) (Alfamine 10\%, Egevet Veterinary Services, Turkey) and $5 \mathrm{mg} / \mathrm{kg}$ of xylazin (Alfazyne 2\%, Egevet Veterinary Services, Turkey) for general anesthesia under the control of a veterinary physician.

\section{Experimental Procedure}

Animals were fixed in the prone position on a board. A midline incision at about the T9 level was performed. After the T8-10 laminectomy, the spinal cord was exposed. The spinal cord of the control group did not undergo any further intervention. The spinal cord of those in the trauma and resveratrol groups was compressed using the aneurysm clip compression technique for 60 seconds; described first by Dolan in 1979 (8). Yasargil's aneurysm clip (FE $740 \mathrm{~K}$ ) with a closing pressure of
$1.43 \mathrm{~N}$ was used. The resveratrol group received $10 \mathrm{mg} / \mathrm{kg}$ of resveratrol IP after the trauma. At the end of the experiment, the animal subjects were given standard bait and free access to tap water and kept in separate cages at $22^{\circ} \mathrm{C}$. The bladders were manually emptied, and bait was kept close to the rats as they were all paraplegic. They were euthanized after 24 hours under the same anesthesia through decapitation, and sections of the vertebral colon from T7 to T11 were removed for further analysis.

\section{Enzyme-Linked Immunosorbent Assay (ELISA)}

Blood was drawn from the animal subjects before euthanasia to measure inflammatory cytokines released in response to trauma. Blood samples were analyzed for TNF-a and IL$1 \beta$ levels at the Department of Pharmacology, Osmangazi University, via ELISA (eBioscience, Bender MedSystems, Vienna, Austria).

\section{Histological Analysis}

All tissue samples were fixed for 24 hours in $10 \%$ formaldehyde at the Department of Pathology, Hitit University. Tissue samples were embedded in paraffin, and $5-\mu \mathrm{m}$ slices were obtained. These sections were stained using hematoxylineosin (H\&E), glial fibrillary acidic protein (GFAP), and terminal deoxynucleotidyl transferase (TdT) dUTP nick-end labeling (TUNEL) methods.

A light microscope (Nikon E200) under 5x magnification field $(\times 400)$ was used; neurons and glial cells were counted under each magnification field. GFAP antibody (Biogen) was used via an automated immunohistochemistry stainer (Ventana). GFAP staining allows visualization of GFAP to confirm the presence of glial cells that increase in number secondary to trauma or malignancy (11). The TUNEL method allows the labeling of deoxyribonucleic acid (DNA) of cells that are undergoing apoptosis by binding TdT to DNA fragments, which are labeled with a marker. The number of apoptotic cells was counted under light microscope (Nikon E200, ×400). Analysis was carried out using computer software by pathologists blinded to the experiment.

\section{Statistical Analysis}

Sigmastat 3.5 (Sysstat Software Inc.) and IBM SPSS Statistics for Windows 21.0 (IBM Corp) were used to analyze the data. Descriptive statistics were presented as mean \pm standard deviation. Given that the comparison of TNF- $a$ and $\mathrm{IL}-1 \beta$ levels yielded a normal distribution, one-way analysis of variance (ANOVA) was performed. Tukey's test was used for multiple comparison tests. Cell counts were compared by using Mann-Whitney $U$ test.

Cell counts were compared using Mann-Whitney $U$ test via IBM SPSS Statistics for Windows 16.0 to analyze the data obtained from histological analysis.

\section{RESULTS}

\section{Biochemical Findings}

TNF- $\alpha$ and IL-1 $\beta$ levels in all groups were measured to evaluate the extent of immune response and correlated apoptosis. The 
resveratrol group had statistically significant lower level of cytokines than the trauma group.

Comparison results showed that the TNF-a means of the trauma group (684.167) is higher and statistically significant than those of the control (45.500) and resveratrol groups (194.167) $(p<0.001)$. However, no statistically significant results were found between the TNF-a means of the resveratrol and control groups $(\mathrm{p}=0.110)$ (Tables I, II).

Comparison results showed that the IL-1 $\beta$ means of the trauma group (791.667) are higher and statistically significant than those of the control (29.167) and resveratrol groups (137.500) $(p<0.001)$. However, no statistically significant results were found between the IL-1 $\beta$ means of the resveratrol and control groups ( $p=0.027$ ) (Tables III, IV).

\section{Histopathological Findings}

Histological analyses of all animal subjects concerning motor neuron, glial cell, and apoptotic cell counts were performed. The resveratrol group had a statistically higher count of motor neuron and glial cells, but no TUNEL positive-stained cells.

Table I: One Way Analysis of Variance - TNF-a

\begin{tabular}{lccccc}
\hline & N & missing & Mean & SD & SEM \\
\hline Control & 6 & 0 & 45.500 & 10.858 & 4.433 \\
\hline Trauma & 6 & 0 & 684.167 & 193.143 & 78.850 \\
\hline Resveratrol & 6 & 0 & 194.167 & 57.829 & 23.608 \\
\hline Source of Variation & DF & SS & F & p & $<0.001$ \\
\hline \multicolumn{1}{c}{ Between Groups } & 4 & 1409587.533 & 352396.883 & 34.740 & $<$ \\
\hline
\end{tabular}

The differences in the mean values among the groups are greater than would be expected by chance; there is a statistically significant difference $(p=<0.001)$.

Table II: Comparison of Means in Accordance with TNF-a using ANOVA Tukey's Test

\begin{tabular}{lccc}
\hline Comparison & Diff of Means & $\mathbf{q}$ & $\mathbf{p}$ \\
\hline Trauma vs. Control & 638.667 & 15.533 & $<0.001$ \\
\hline Trauma vs. Resveratrol & 490.000 & 11.917 & $<0.001$ \\
\hline Resveratrol vs. Control & 148.667 & 3.616 & 0.110 \\
\hline
\end{tabular}

Table III: One Way Analysis of Variance - IL $1 \beta$

\begin{tabular}{lccccc}
\hline & N & missing & Mean & SD & SEM \\
\hline Control & 6 & 0 & 29.167 & 7.360 & 3.005 \\
\hline Trauma & 6 & 0 & 791.667 & 93.095 & 38.006 \\
\hline Resveratrol & 6 & 0 & 137.500 & 60.725 & 24.791 \\
\hline Source of Variation & DF & SS & MS & F & p \\
\hline Between Groups & 4 & 2128188.333 & 532047.083 & 156.400 & $<0.001$ \\
\hline
\end{tabular}

The differences in the mean values among the groups are greater than would be expected by chance; there is a statistically significant difference $(p=<0.001)$.

Table IV: Comparison of Means in Accordance with IL-1 $\beta$ using ANOVA Tukey's Test

\begin{tabular}{lccc}
\hline Comparison & Diff of Means & $\mathbf{q}$ & $\mathbf{p}$ \\
\hline Trauma vs. Control & 762.500 & 32.023 & $<\mathbf{0 0 1}$ \\
\hline Trauma vs. Resveratrol & 654.167 & 27.473 & $<\mathbf{0 0 1}$ \\
\hline Resveratrol vs. Control & 108.333 & 4.550 & $\mathbf{0 . 0 2 7}$ \\
\hline
\end{tabular}


When the motor neuron cells in the trauma group (4.06) were compared with those of the control (13.05) and resveratrol (9.05) groups, the results were statistically significant $(p=0.001$ and 0.006). However, when the control and resveratrol groups were compared, no statistically significant difference was found $(p=0.472)$. Resveratrol protected the number of motor neuron cells significantly than the trauma group (Figure 1A-D).

When the glial cells in the trauma group (4.5) were compared with the control (13.5) and resveratrol (8.5) groups, the results were statistically significant $(p=0.000$ and 0.02$)$. Moreover, the number of glial cells in the resveratrol group was lower and statistically significant than the control group (8.5 vs. 13.5) $(p=0.02)$ (Figure $2 A-C)$.

TUNEL-positive-stained apoptotic cells were observed mainly in the trauma group, whereas the control and resveratrol groups did not show any significant positive staining (Figure $3 A-D)$.

\section{DISCUSSION}

The results obtained from this study sheds novel insights into the pathology and potential treatment of SCl. This study supports resveratrol's anti-inflammatory and anti-apoptotic effects through biochemical and immunohistochemical analyses. Resveratrol had a great effect on reducing proinflammatory cytokines TNF- $\alpha$ and IL-1 $\beta$, and the effects were visualized through histological examination, which showed increased glial and motor neuron cell counts with decreased apoptosis compared with the trauma group.

Resveratrol diminishes the oxidation of low-density lipoproteins by eliminating oxygen-free radicals. It proves to have anti-inflammatory, anti-bacterial, and anti-apoptotic effects by altering arachidonic acid metabolism and inhibiting protein kinase activities (27). Moreover, a previous study has reported this effect along with alleviating hemorrhage and edema in neural tissue while also reversing tissue necrosis and apoptosis (29). In addition, another report revealed resveratrol's effect of partially restoring normal functions in neurons, most
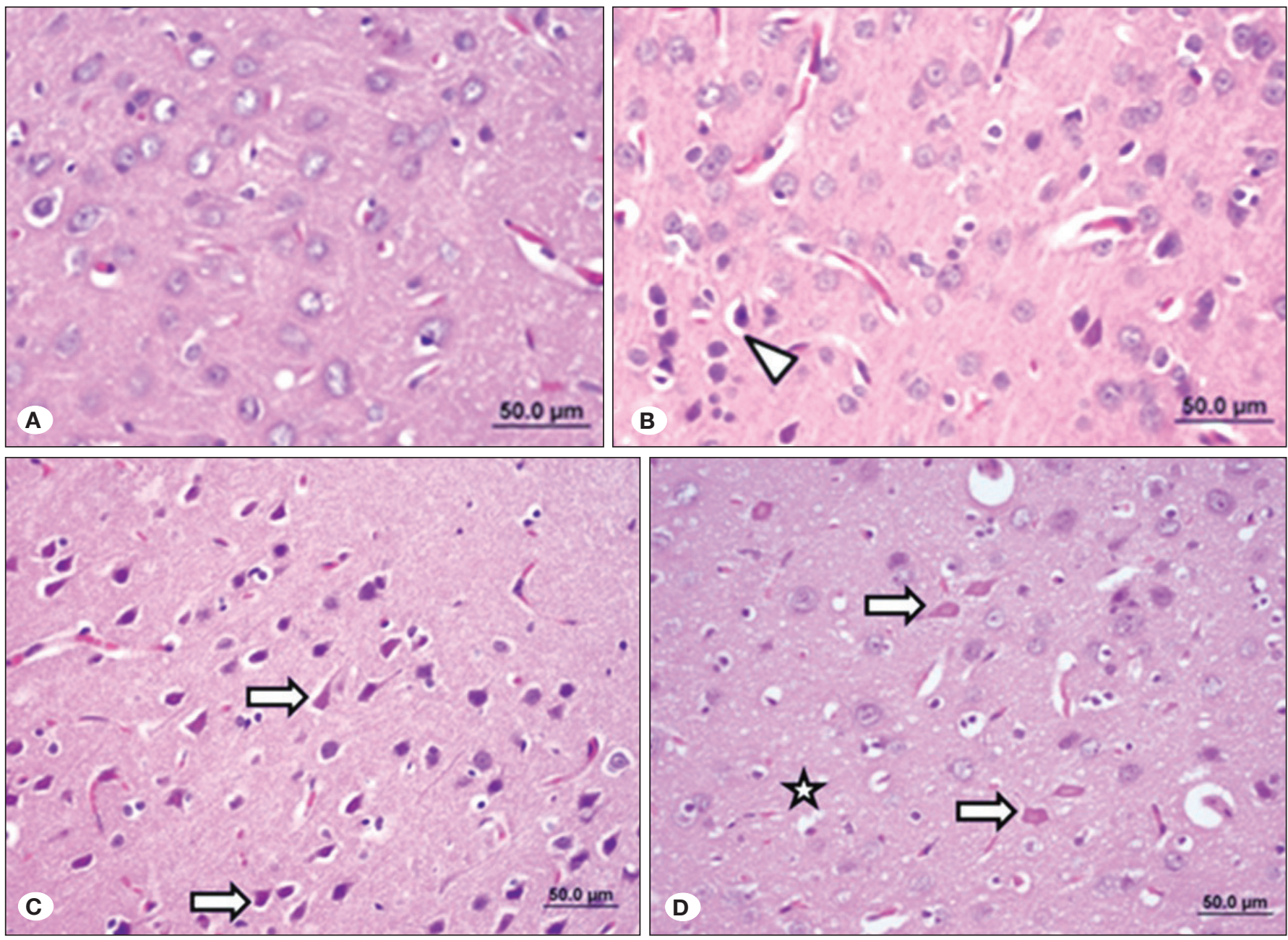

Figure 1: Hematoxylin \& Eosin Stain: Motor Neuron Cell Count. Spinal cord tissue morphology with hematoxylin \& eosin staining (H\&E, scale bar: $50.0 \mu \mathrm{m})$. A) Control Group: Section through the spinal cord showing normal distribution of cells. B) Resveratrol Group: Generally normal distribution of cells along with minimal necrotic neurons $(\Delta)$ with pericapillary edema. C,D) Trauma Group: Significant numbers of necrotic neurons (arrow) along with cellular loss (star) are observed. 

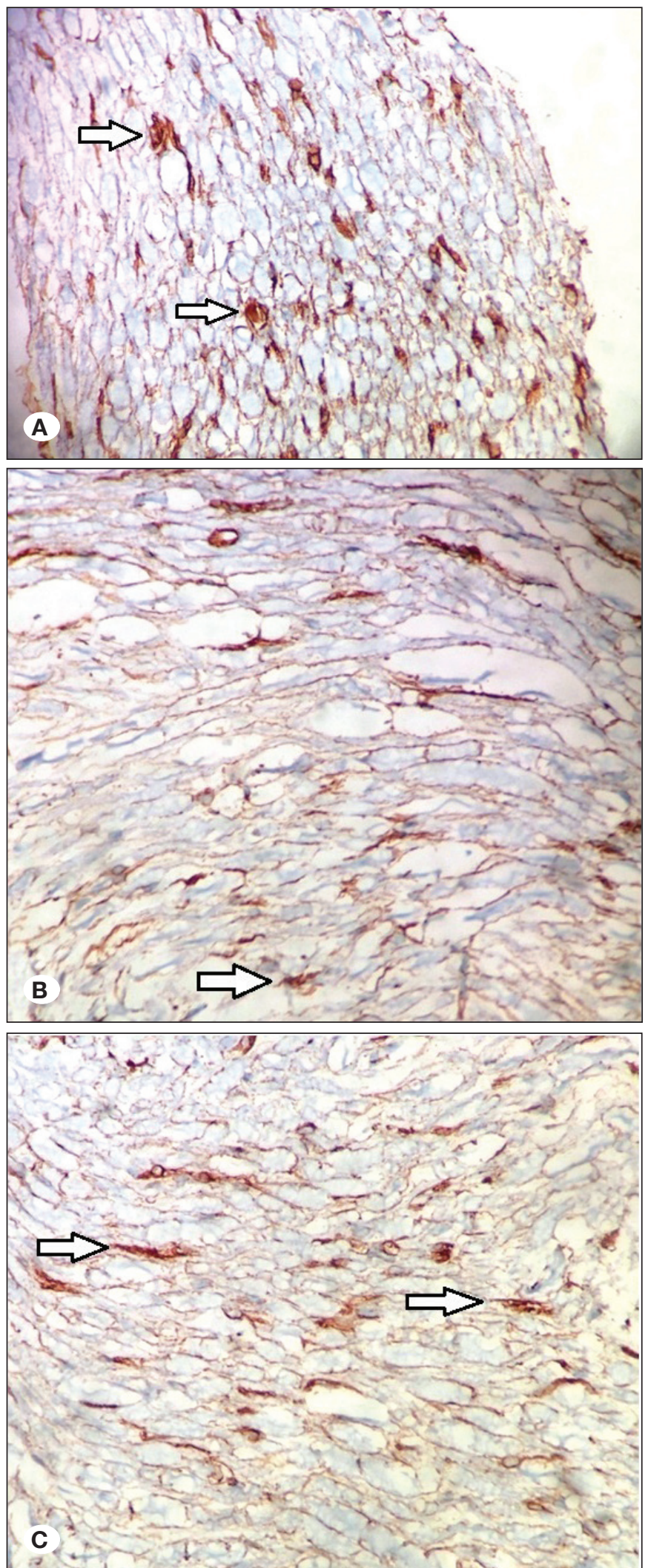

Figure 2: GFAP Stain: Glial Cell Count. Sections of the spinal cord stained with an immunoperoxidase stain for GFAP. A) Control group, B) Trauma group, C) Resveratrol Group. GFAP positive stains of glial cells are indicated by arrows. notably in the areas of cellular nutrient supply and energy biosynthesis (17).

Higher doses of resveratrol (100 mg/kg IP) have shown promising anti-inflammatory effects by reducing malondialdehyde (MDA). The same study revealed that with an even higher dose (200 mg/kg IP), the antioxidant effects become more apparent by reducing xanthine oxidase and nitric oxide levels while increasing superoxide dismutase (SOD) activity and glutathione peroxidase (GSH) levels (3).

In the present experimental study on 18 rats, three randomized groups were used to evaluate the effects of resveratrol on spinal cord trauma. Biochemical analysis was performed to measure the levels of TNF- $\alpha$ and IL-1 $\beta$, which have been increased after spinal trauma and majorly constituted the secondary phase of SCl, such as inflammation (1). The TNF-a means of the trauma group (684.167) was statistically higher than the resveratrol group (194.167) $(p<0.001)$. Resveratrol has been previously shown to reduce inflammation by decreasing TNFa-induced activation of mitogen-activated protein kinases and nuclear factors that eventually reduced expression of intercellular adhesion molecule 1 (ICAM-1) and adhesion of monocytes (18). The biochemical parameters obtained in the present study in parallel with the recent literature has shown resveratrol's anti-inflammatory effects on spinal cord after trauma, which may prove to be beneficial in reducing the damage caused by the secondary phase of $\mathrm{SCl}$.

A pilot study conducted on 23 patients with $\mathrm{SCI}$ revealed that both TNF- $a$ and IL-1 $\beta$ levels were correlated with recovery status as patients with better overall outcome had lower levels of both cytokines (5). This is the reason that the present study focused only on these two cytokines. The results obtained in the present study also reported a statistically significant $(p<0.001)$ lower value of IL-1 $\beta$ in the resveratrol group (137.500) than the control group (791.667). Another study that has focused on inflammation and apoptosis after $\mathrm{SCl}$ has stressed the importance of upregulated cytokines beginning as early as 30 minutes after the initial trauma starts an inflammatory cascade that develops exponentially, leading to the destruction of the remaining healthy neural tissues (28). Thus, several studies have focused on reducing the overexpressed inflammation after $\mathrm{SCl}$, and the present study support resveratrol's effects on reducing both inflammation and apoptosis. A recent comprehensive paper proposed two different treatment modalities to evaluate the effects of resveratrol on traumatic brain injury on rats. Low- and highdose treatments were given daily (50 and $100 \mathrm{mg} / \mathrm{kg}$ per day). Multiple biochemical analyses were performed to measure MDA, SOD, GSH, and 8-OHdG/106 dG (oxidative DNA damage) levels. All parameters were found to be higher in the trauma group, suggesting the protective and possible healing effect of resveratrol after traumatic brain injury. No statistically significant difference was found between the high- and lowdose treatments, suggesting that resveratrol may prove beneficial even at low doses (2). The results obtained from the present study proved the beneficial results of resveratrol even at $10 \mathrm{mg} / \mathrm{kg}$ dose. 


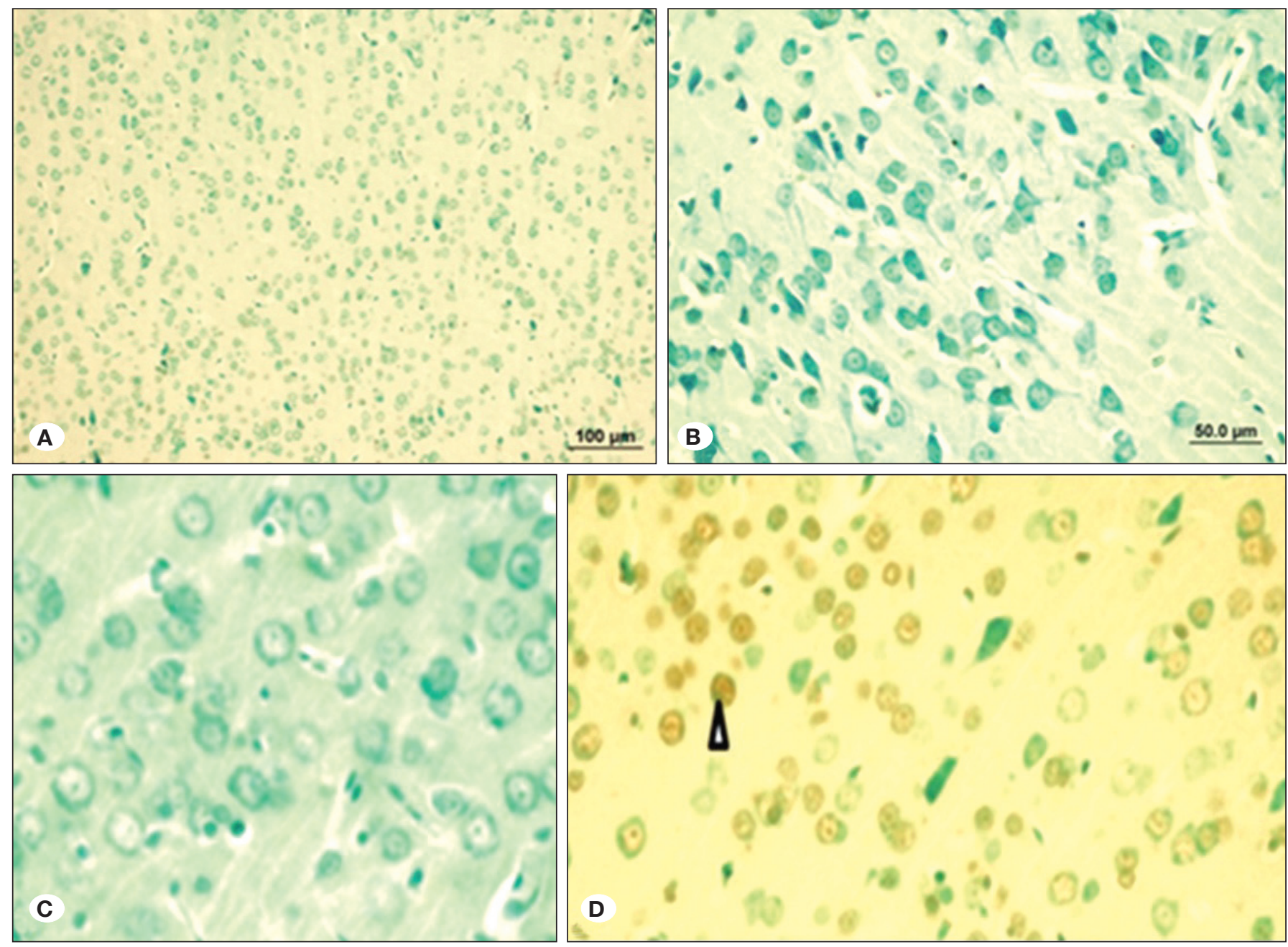

Figure 3: TUNEL Assay: Apoptotic Cell Count. TUNEL stained sections of the spinal cord. A, B) Resveratrol group: Negative staining

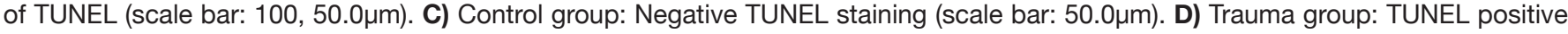
stained cells indicated by arrow (scale bar: $50.0 \mu \mathrm{m})$.

The TUNEL staining method allows the labeling of DNA of cells that are undergoing apoptosis by binding TdT to DNA fragments that are labeled with a marker. In a study using electron microscope identification and TUNEL staining, the resveratrol group showed a statistically significant decreased number of TUNEL-positive cells. Moreover, the resveratrol group showed the effects of improving abnormal cellular morphology by the inhibition or reduction in neuronal shrinkage, disappearance of mitochondrial ridges, cytoplasm vacuolization, and enlargement of the endoplasmic reticulum, which all contribute to a cell's path toward apoptosis (17).

Resveratrol has also been shown to inhibit the upregulation of pro-apoptotic factor Bax and terminal executing enzymes for substrate cleavage of caspase-3. Moreover, the downregulation of anti-apoptotic factor $\mathrm{Bcl}-2$ after $\mathrm{SCl}$ was inhibited (17). Another study reported that resveratrol could prevent apoptosis in neurons by activating the PI3K/Akt pathway (30). These effects can be contributed to the anti-apoptotic effect of resveratrol. A larger series of subjects evaluated resveratrol's effects on transient cerebral ischemia in 60 rats; similar to the present study, TUNEL staining was obtained along with $\mathrm{H} \& \mathrm{E}$, NeuN analysis, and Western Blot to determine Bcl-2, Bax, and caspase- 3 levels. The rats received $30 \mathrm{mg} / \mathrm{kg} \mathrm{IP}$ of resveratrol similar to the present study but were given treatment consecutively for 7 days before the procedure (19). This crucial study supports resveratrol's neuroprotective effects by inhibiting neuronal apoptosis. In addition, the administration of resveratrol before the procedure may prove its prophylactic effect on cerebral ischemia.

The present experimental study provides support for the antiapoptotic mechanisms of resveratrol through histological analysis. The resveratrol group had no TUNEL-positive stains, whereas the trauma group had positive stains displaying cells that were undergoing apoptosis. In addition, H\&E and GFAP staining showed that compared with the trauma group's motor neuron cell (4.06) and glial cell (4.5) counts, the treatment groups had a better outcome with 9.05 and 8.50 , respectively. Both comparisons yielded a statistically significant result $(p=0.001)$. 


\section{CONCLUSION}

The present experimental study on rats following $\mathrm{SCI}$ focuses on major issues correlated with inflammation and apoptosis after the initial trauma, which constitutes the major portion of the secondary phase of $\mathrm{SCl}$. Complications of $\mathrm{SCl}$ are catastrophic, and there is no definitive cure available. From a neurosurgical perspective, decompressing the spinal cord and stabilizing the vertebral column are long-term methods of helping the patient to recover. Many areas of multistep and complex physiological processes remain to be enlightened. Current therapeutic interventions aim at minimizing the inflammatory and apoptotic process after the initial trauma. The present experimental study supports the use of resveratrol in SCl given its anti-inflammatory and anti-apoptotic effects. Nonetheless, the present study is just a drop in the ocean as $\mathrm{SCl}$ is a boundless sea. The authors hope that the results obtained here support the development of new approaches in $\mathrm{SCl}$ treatment by providing a framework. Much work through clinical trials is needed to ascertain whether any of the therapies at hand are beneficial.

\section{ACKNOWLEDGEMENT}

We thank our colleagues from Eskisehir Osmangazi University School of Medicine Department of Pharmacology who provided insight and expertise that greatly assisted the research. We would also like to show our gratitude to the Eskisehir Osmangazi University School of Medicine Department of Pharmacology for sharing their pearls of wisdom with us during the course of this research.

\section{- REFERENCES}

1. Amar AP, Levy ML: Pathogenesis and pharmacological strategies for mitigating secondary damage in acute spinal cord injury. Neurosurgery 44: 1027-1040, 1999

2. Atalay T, Gulsen I, Colcimen N, Alp HH, Sosuncu E, Alaca I, Ak $\mathrm{H}$, Ragbetli MC: Resveratrol treatment prevents hippocampal neurodegeneration in a rodent model of traumatic brain injury. Turk Neurosurg 27(6): 924-930, 2017

3. Ates O, Cayli S, Altinoz E, Gurses I, Yucel N, Kocak A, Yologlu $\mathrm{S}$, Turkoz Y: Effects of resveratrol and methylprednisolone on biochemical, neurobehavioral and histopathological recovery after experimental spinal cord injury. Acta Pharmacol Sin 27: 1317-1325, 2006

4. Athar M, Back JH, Tang X, Kim KH, Kopelovich L, Bickers DR, Kim AL: Resveratrol: A review of preclinical studies for human cancer prevention. Toxicol Appl Pharmacol 224: 274-283, 2007

5. Biglari B, Swing T, Child C, Büchler A, Westhauser F, Bruckner T, Ferbert $T$, Jürgen Gerner $H$, Moghaddam A: A pilot study on temporal changes in IL-1 $\beta$ and TNF- $\alpha$ serum levels after spinal cord injury: The serum level of TNF-a in acute SCl patients as a possible marker for neurological remission. Spinal Cord 53: 510-514, 2015

6. Carter LG, D'Orazio JA, Pearson KJ: Resveratrol and cancer: Focus on in vivo evidence. Endocr Relat Cancer 21: 209-225, 2014
7. Ciftci U, Delen E, Vural M, Uysal O, Turgut Cosan D, Baydemir C, Doganer F: Efficiacy of resveratrol and quercetin after experimental spinal cord injury. Ulus Travma Acil Cerrahi Derg 22: 423-431, 2016

8. Dolan EJ, Tator $\mathrm{CH}$ : A new method for testing the force of clips for aneurysms or experimental spinal cord compression. J Neurosurg 51: 229-233, 1979

9. Fallah A, Dance D, Burn AS: Rehabilitation of the individual with spinal cord injury. In: Fehlings MG, Vaccaro AR, Maxwell B (eds). Essentials of Spinal Cord Injury: Basic Research to Clinical Practice. Thieme, 2012: 235

10. Fremont L: Biological effects of resveratrol. Life Sci 66(8): 663-673, 2014

11. Garrison CJ, Dougherty PM, Kajander KC, Carlton SM: Staining of glial fibrillary acidic protein (GFAP) in lumbar spinal cord increases following a sciatic nerve constriction injury. Brain Res 565(1): 1-7, 1991

12. Janssen L, Hansebout RR: Pathogenesis of spinal cord injury and newer treatments. A review. Spine (Phila Pa 1976) 14(1): 23-32, 1989

13. Kaplan S, Bisleri G, Morgan JA, Cheema FH, Oz MC: Resveratrol, a natural red wine polyphenol, reduces ischemiareperfusion-induced spinal cord injury. Ann Thorac Surg 80: 2242-2249, 2005

14. Kesherwani V, Atif F, Yousuf S, Agrawal SK: Resveratrol protects spinal cord dorsal column from hypoxic injury by activating Nrf-2. Neuroscience 25: 80-88, 2013

15. Lagouge M, Argmann C, Gerhart-Hines Z, Meziane H, Lerin C, Daussin F, Messadeq N, Milne J, Lambert P, Elliott P, Geny B, Laakso M, Puigserver P, Auwerx J: Resveratrol improves mitochondrial function and protects against metabolic disease by activating SIRT1 and PGC-1alpha. Cell 127: 1109-1122, 2006

16. Lifshutz J, Colohan A: A brief history of therapy for traumatic spinal cord injury. Neurosurg Focus 16: E5, 2004

17. Liu C, Shi Z, Fan L, Zhang C, Wang K, Wang B: Resveratrol improves neuron protection and functional recovery in rat model of spinal cord injury. Brain Res 1374: 100-109, 2011

18. Liu CW, Sung HC, Lin SR, Wu CW, Lee CW, Lee IT, Yang YF, Yu IS, Lin SW, Chiang MH, Liang CJ, Chen YL: Resveratrol attenuates ICAM-1 expression and monocyte adhesiveness to TNF-a-treated endothelial cells: Evidence for an antiinflammatory cascade mediated by the miR-221/222/AMPK/ p38/NF-kB pathway. Sci Rep 7: 44689, 2017

19. Liu S, Sun J, Li Y: The neuroprotective effects of resveratrol preconditioning in transient global cerebral ischemiareperfusion in mice. Turk Neurosurg 26(4): 550-555, 2016

20. Lopez MS, Dempsey RJ, Vemuganti R: Resveratrol neuroprotection in stroke and traumatic CNS injury. Neurochem Int 89: 75-82, 2015

21. Morganti-Kossmann C, Raghupathi R, Maas A: Traumatic brain and spinal cord injury: Challenges and developments. Cambridge University Press, 2012: 229

22. Pathak L, Agrawal Y, Dhir A: Natural polyphenols in the management of major depression. Expert Opin Investig Drugs 22(7): 863-880, 2013 
23. Stervbo U, Vang O, Bonnesen C: A review of the content of the putative chemopreventive phytoalexin resveratrol in red wine. Food Chem 101(2):449-457, 2007

24. Szmitko PE, Verma S: Cardiology patient pages. Red wine and your heart. Circulation 111(2):e10-11, 2005

25. Takaoka M: Resveratrol, a new phenolic compound, from Veratrum grandiflorum. J Chem Soc Japan 60(11):1090-1100, 1939

26. Turner RS, Thomas RG, Craft S, van Dyck $\mathrm{CH}$, Mintzer J, Reynolds BA, Brewer JB, Rissman RA, Raman R, Aisen PS: Alzheimer's Disease Cooperative Study. A randomized, double-blind, placebo-controlled trial of resveratrol for Alzheimer disease. Neurology 85(16):1383-1391, 2015
27. Yang YB, Piao YJ: Effects of resveratrol on secondary damages after acute spinal cord injury in rats. Acta Pharmacol Sin 24(7):703-710, 2013

28. Zhang N, Yin Y, Xu SJ, Wu YP, Chen WS: Inflammation \& apoptosis in spinal cord injury. Indian J Med Res 135(3): 287296, 2012

29. Zhang Q, Yang H, An J, Zhang R, Chen B, Hao DJ: Therapeutic effects of traditional Chinese Medicine on spinal cord injury: A promising supplementary treatment in future. Evid Based Complement Alternat Med 2016: 8958721, 2016

30. Zhou XM, Zhou ML, Zhang XS, Zhuang Z, Li T, Shi JX, Zhang $X$ : Resveratrol prevents neuronal apoptosis in an early brain injury model. J Surg Res 189(1):159-165, 2014 